\title{
APPLICATION OF IONIC LIQUIDS IN THE ULTRASOUND-ASSISTED EXTRACTION OF ANTIMICROBIAL COMPOUNDS FROM THE BARK OF CINNAMOMUM CASSIA
}

\author{
ALICJA MICHALCZYK', ANNA CIENIECKA-ROSŁONKIEWICZI, \\ MALGORZATA CHOLEWIŃSKA ${ }^{2}$
}

\begin{abstract}
${ }^{1}$ Department of Pesticide Use and Formulation, Institute of Industrial Organic Chemistry, Poland,
${ }^{2}$ Department of Synthesis and Technology, Institute of Industrial Organic Chemistry, Poland,
\end{abstract}

\begin{abstract}
This study compares the chemical constituents of extracts from the bark of Cinnamomum cassia obtained with the use of ionic liquids and organic solvents, as well as investigates their antifungal and yeasticidal activity. The type of ionic liquid was found to play a significant role in this process. We found that the ionic liquid tris (2-hydroxyethyl) methylammonium methylsulfate is a most efficient extracting agent, superior to classical solvents such as ethanol, ethyl acetate, hexane, dichloromethane. The obtained extract revealed high antimicrobial activity against yeasts, fungi pathogenic for plants and bees, dermatophytes, filamentous moulds with similar potencies as the standard fungicides.
\end{abstract}

Keywords: Cinnamomum cassia, Ionic liquids, Antifungal activity, Chemical composition

\section{INTRODUCTION}

Cinnamomum cassia (syn. C. aromatica), also named Chinese cinnamon is an evergreen tropical tree, belonging to the Lauraceae family. It is one of the most important spices which has been traditionally used in treatment of gastritis, blood circulation disorders, dyspepsia, inflammatory diseases ${ }^{1,2}$ such as influenza and arthritis ${ }^{3}$. The essential oil and extracts obtained from the bark, young branches and leaves of this plant have excellent inhibitory effects against bacteria ${ }^{4}$ and fungi ${ }^{5-9}$ In addition, extracts from C. cassia bark inhibited skin and pulmonary tumours as well as the growth of gastric, colon and cervical cell cancer lines ${ }^{10}$. The oil and extracts from $C$. cassia exhibited high toxicity to adult beetles of the stored product pests, Lasioderma serricorne, Sitophilus oryzae and Callosobruchus chinensis ${ }^{11}$ and can also be used as potential repellents against Aedes aegypti ${ }^{12}$, Delia radicum ${ }^{13}$ and Alphitobius diaperinus ${ }^{14}$. These unique properties of extracts and oil of cinnamon are associated with their chemical composition. The major bioactive components of $C$. cassia are as follows cinnamaldehyde, terpenes, aromatic compounds and esters.

A variety of developed extraction techniques play a key role in the separation and analysis of bioactive compounds from plant material. The extraction of antimicrobial components from C.cassia bark has been carried out by several extraction methods. These include heating reflux extraction ${ }^{15}$, maceration at room temperature ${ }^{16}$ and Soxhlet extraction ${ }^{17}$ with water, methanol, ethanol, petroleum ether, hexane, dichloromethane and some mixtures such as solvents. The applied organic solvents are usually flammable, toxic and volatile, so they are extremely dangerous for the environment. In this work, we propose ionic liquids as a green alternative to conventional organic solvents.

Ionic liquids (ILs) also known as molten salts, composed of organic cations and inorganic or organic anions are liquid at approx room temperature (or by convention below $100^{\circ} \mathrm{C}$ ) ${ }^{18}$. Ionic liquids have unique properties such as negligible vapor pressure, good thermal stability, relatively low toxicity, good ultrasonic absorbing ability. In addition, ionic liquids have a large electrochemical window and excellent solvent properties for a wide range of inorganic and organic materials ${ }^{19}$, which makes them a very interesting subject of research. Over the last few years, ionic liquids have been offered as extrahents of ions of various metals from alkali through heavy ${ }^{20-22}$ to radioactive metals ${ }^{23}$. Phenolic compounds, amino acids, hydrocarbons in mixtures and food dyes in water solutions can be also effectively extracted to ionic liquid. Moreover, desulphurization of gas oils and gasoline by extraction with these salts is also possible ${ }^{24,25}$.

Recently, ionic liquids ( ILs) have been used as solvents for the effective extraction of active metabolites from plants, for instance to obtain: polyphenolic compounds such as; trans-resveratrol from Rhizma Polygoni Cuspidati ${ }^{26}$, saponins from Dioscorea zingiberensis ${ }^{27}$, rutin from Saururus chinensis ${ }^{28}$ and piperine from white pepper ${ }^{29}$, three alkaloids N-nornuciferine, O-nornuciferine, and nuciferine from lotus leaf ${ }^{30}$, insecticidal as well as microbiocidal compounds of the fungus Cantharellus cibarius ${ }^{31}$. The purpose of this study was to use ammonium- based ionic liquids for the extraction of secondary metabolites from the bark of Cinnamomum cassia. The chemical composition of the obtained extracts and the activity against fungi and yeast were determined.

\section{MATERIALS AND METHODS}

\section{Plant material}

The dried bark of Cinnamomum cassia produced in China was purchased from a local market in Poland. A voucher of specimen (38 GS15) was stored in the laboratory for further reference. The bark was ground to powder in a sterile coffee mill before extraction.

\section{Chemicals}

Figure 1. Structures of ionic liquids used in the extraction process; Benzalconium lactate- $\boldsymbol{A}$, Didecyldimethyl lactate- $\boldsymbol{B}$, Benzalconium nitrate- $\boldsymbol{C}$, Didecyldimetthyl nitrate- $\boldsymbol{D}$, Tris(2-hydroxyethyl)methylamonium methylsulfate- $\boldsymbol{E}$.

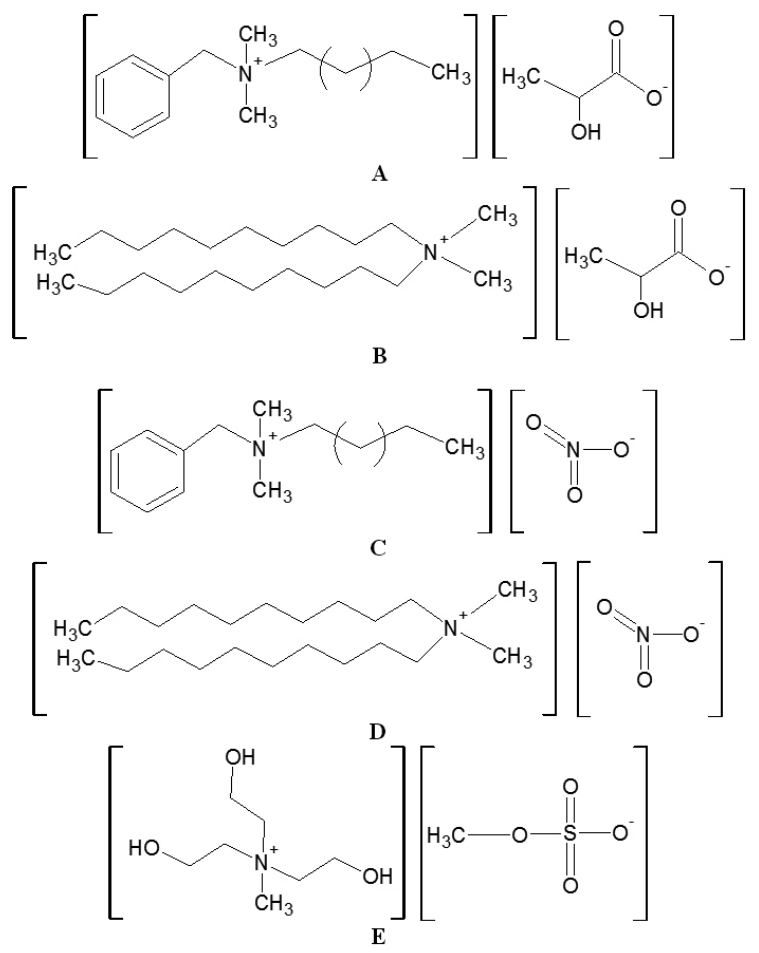

Figure 1 lists the four ammonium -based ionic liquids 1-4 used in this work, which were prepared in high yields (efficiency of over 95\%) according to the procedure presented in the literature. ${ }^{32,33}$. Tris (2-hydroxyethyl) methylammonium methylsulfate (5), cinnamaldehyde, coumarin, ketoconazole were purchased from Aldrich (USA). 


\section{Extraction of plant material}

The plant material underwent extraction using a classic method of isolating active substances sensitive temperature, called maceration. In order to increase the efficiency of obtaining active compounds, the ultrasonic bath Sonorex Super RK $512 \mathrm{H}$ generating ultrasounds of $35 \mathrm{~Hz}$ frequency was used was used. The extraction was carried out using equal amounts of powdered biological material $(25 \mathrm{~g})$. The evaporation of organic solvents from the extracts was carried out using a vacuum evaporator at $30-40^{\circ} \mathrm{C}$.

\section{Extraction with organic solvents}

First, $50 \mathrm{ml}$ of organic solvent (ethyl acetate, hexane, methylene chloride, methanol) was poured over the dried and ground plant material in the amount of $25 \mathrm{~g}$, the material was then placed in an ultrasonic bath for $2 \times 10$ minutes and put away for 3 days (stirred occasionally). The whole extraction process took place at ambient temperature $\left(20^{\circ} \mathrm{C}\right)$. After filtering the constant residues in a Schott funnel, the filtrate was dried by vaporization of solvents with a vacuum evaporator. The obtained extracts were then used in chemical and biological analyses.

\section{Extraction with ionic liquids}

First, $50 \mathrm{ml}$ of ionic liquid was poured over a specified amount of dried and powdered bark of the cinnamon tree, then the bark was placed in the ultrasonic bath for $2 \times 10$ minutes and put away for 3 days (stirred occasionally). The whole extraction process took place at ambient temperature $\left(20^{\circ} \mathrm{C}\right)$. At the subsequent stage, the constant residues were filtered in a Schott funnel. The ionic liquid solution was then mixed up with hexane, its layers were separated and the solvent was vaporized from the layer of hexane using an evaporator. The obtained extracts were then used in chemical and biological analyses.

\section{GC-MS analysis conditions}

The analyses of the extracts of C.cassia bark were performed using GC/ MS system consisting of a Varian 450-GC gas chromatograph (Varian, USA), Varian 320 MS mass detector (Varian USA) and CP-8400 auto sampler. A VF5 MS capillary column (Varian, USA) ( $30 \mathrm{mx} 0.25 \mathrm{~mm}, 0.25 \mu \mathrm{m}$ film thickness) was used with helium as the carrier gas, at a flow rate of $0.5 \mathrm{ml} / \mathrm{min}$ at a split ratio of 1:100. The $\mathrm{GC}$ oven temperature was programmed at an initial value of $50^{\circ} \mathrm{C}$ for $1 \mathrm{~min}$, then heated up to $250^{\circ} \mathrm{C}$ at $4^{\circ} \mathrm{C} / \mathrm{min}$, and kept at $250^{\circ} \mathrm{C}$ for 10 $\mathrm{min}$. The injector and detector temperatures were set at $250^{\circ} \mathrm{C}$. Diluted samples $(1: 100 \mathrm{v} / \mathrm{v}$, in hexane) of 1.0 were injected automatically. Mass spectrometry was run in the electron impact mode (EI) at $70 \mathrm{eV}$. The qualitative analysis was carried out on the basic of MS spectra which were compared with the spectra of the NIST (2002), LIBR (TR) (1990) database and the data available in the literature ${ }^{34,35}$. Retention indices for all the compounds were determined according to the Kovats method ${ }^{36,37}$ using n-alkanes as standards $\left(\mathrm{C}_{6}-\mathrm{C}_{40}\right.$. The compounds were identified by comparing the Kovats indices with those reported in the literature ${ }^{37,38}$.

\section{Evaluation of antimicrobial activity}

The antimicrobial activity of the $C$. cassia extracts and its major components: cinnamaldehyde and coumarin were tested against yeasts and fungi.

\section{Microbial strains and culture media}

The activity of C. cassia extracts was evaluated against the following fungal and yeasts species: plant pathogenic fungi: Alternaria alternata (Fries) Keissler, Fusarium culmorum (Smith) Saccardo, Gaeumannomyces Graminisvar tritici, Rhizoctonia solani Kuhn, Phytophthora cactorum (Lebert et Cohn) Schroeter, Fusarium graminearum Schwabe, fungus causing ascosphaeriosis in bees: Ascosphaera apis ATCC 13785, dermatophytes causing human and animal skin dermatosis: Trichophyton mentagrophytes ATCC 9533, Microsporum gypseum ATCC 6231, Microsporum cookei ATCC 13275, fungi causing microbial corrosion of materials (filamentous): Aspergillus niger (ŁOCK 0439), Chaetomium globosum (LOCK 0476), Paecilomyces variotii (ŁOCK 0525), Scopulariopsis brevicaulis (LOCK 0553), yeasts: Candida albicans ATCC 10231 and Rhodotorula rubra (syn. R. mucilaginosa) ATCC 20129, Malassezia furfur ATCC 14521.

The dermatophytes, yeasts and Ascosphaera apis were supplied by the American Type Culture Collection (ATCC), USA. The plant pathogenic fungi were obtained from the Department of Phytopathology and Entomology, University of Warmia and Mazury in Olsztyn, Poland. Fungi causing microbial corrosion of materials were purchased from the Institute of Fermentation Technology and Microbiology, Łódź University of Technology. All fungal strains (with the exception of plant pathogenic fungi) were cultured on
Sabouraud Dextrose Agar (SDA, Oxoid) at $28^{\circ} \mathrm{C}$ for $4-7$ days. The strains that cause plant diseases were kept on potato dextrose agar (PDA, Oxoid) at $25^{\circ} \mathrm{C}$ for 7-10 days. The test strains were kept on agar slants, stored in a refrigerator at $4^{\circ} \mathrm{C}$ and were transferred every 5-8 weeks to a fresh medium.

\section{Yeasticidal activity}

The assays against yeasts were carried out using the disc diffusion method which was applied for the determination of antibacterial and yeasticidal activity of the essential oil and the plant extracts ${ }^{39,40}$. The extracts from $C$. cassia, cinnamaldehyde and coumarin were dissolved in acetone to obtain the concentration of $5 \mathrm{mg} / \mathrm{ml}$. Sterile filter paper discs ( $5 \mathrm{~mm}$ in diameter) were impregnated with $50 \mu 1$ of prepared extracts or reference substances and were then dried in a laminar flow cabinet at room temperature to evaporate the acetone. The dried paper discs were placed in $9 \mathrm{~cm}$ Petri dishes containing Sabouraud dextrose agar (SDA, Oxoid) cultured with the appropriate yeast strains. Petri dishes were placed at $4^{\circ} \mathrm{C}$ for $2 \mathrm{~h}$ to allow the extracts and constituents to diffuse into the medium and then incubated at $28^{\circ} \mathrm{C}$ for 48 hours. The disc soaked in $50 \mu \mathrm{l}$ acetone and then dried, served as the negative control. As the positive control, ketoconazole $(5 \mathrm{mg} / \mathrm{ml})$, a commercially available fungicide was used. The diameters of the inhibition zones were measured in millimetres. The size of the inhibition zone was proportional to the inhibitory activity of the tested sample. The experimental studies were repeated three times.

\section{Antifungal activity}

The experiments were carried out according to a slightly modified standard method used in laboratory investigations of fungicides ${ }^{41}$. The tested compounds were dissolved in acetone and added to a sterile Sabouraud Dextrose Agar (SDA) or Potato Dextrose Agar (PDA) medium to obtain the concentration of $5 \mathrm{mg} / \mathrm{ml}$. The control sample contained acetone only. The media were poured onto $90 \mathrm{~mm}$ Petri dishes. When acetone evaporated, $5 \mathrm{~mm}$ discs of 5-7 -dayold test fungi were placed in the middle of the Petri dishes. The dishes were incubated in the dark at $25 \pm 1{ }^{\circ} \mathrm{C}$ (plant pathogenic fungi, Ascosphaera apis, dermatophytes) and $28{ }^{\circ} \mathrm{C}$ (filamentous fungi) for a period of 4-7 days. As a reference, ketoconazole was used. After incubation, the diameters of the cultures were measured. The growth of fungi on media containing the tested compound was compared to the control ones. The percentage of fungal growth inhibition was calculated according to the Abbot formula:

$$
I(\%)=\frac{d_{\mathrm{c}}-d_{\mathrm{t}}}{d_{\mathrm{c}}} \times 100
$$

$\mathrm{d}$ : the diameter of mycelium growth in the control plate

$d_{t}$ : the diameter of mycelium growth in the experimental dish (mm)

The following evaluation scale was used:

1-efficacy $\quad 0-20 \% \quad$-not active

2-efficacy $\quad 21-50 \% \quad$-weak activity

3-efficacy $\quad 51-80 \% \quad$-medium activity

4-efficacy $\quad 81-100 \%$-good activity

Statistical analysis

The Scheffe method of SAS was used to analyse the difference of yeasticidal and antifungal properties among nine C.cassia bark extracts and their main components $(\mathrm{p}<0.05)$

\section{RESULTS AND DISCUSION}

\section{Yields and chemical composition of the extracts from $C$. cassia bark}

The effectiveness of active compounds extracted from C. cassia bark was found to be dependent on the kind of ionic liquids applied (Table 1). The highest amount of extract was obtained with the classical solvents: ethanol, ethyl acetate, hexane and dichloromethane. Slightly lower amounts of extract were obtained when using ionic liquids (E) or (A) and (D). The lowest amounts were obtained with the ionic liquid (B) which contains lactate as anion and didecyldimethyl as cation. 
Table 1. Effectiveness of various ionic liquids and classical solvents for extraction of active compounds from Cinnamomum cassia bark.

\begin{tabular}{|c|c|c|}
\hline Extract & Extraction solvent & Yield of extraction [g] \\
\hline I & A & 0.244 \\
\hline II & B & 0.118 \\
\hline III & C & 0.138 \\
\hline IV & $\mathbf{D}$ & 0.236 \\
\hline V & $\mathbf{E}$ & 0.35 \\
\hline VI & Hexane & 0.405 \\
\hline VII & Ethyl acetate & 1.237 \\
\hline VIII & Dichloromethane & 0.65 \\
\hline IX & Ethanol & 2.2 \\
\hline
\end{tabular}

The chemical composition of extracts from the bark of C. cassia was analysed using GC-MS. The percentage content of each component in the analyzed extracts with the retention times is shown in Table 2.

Table 2. Chemical composition of the extracts from bark of Cinnamomum cassia prepared by different solvents (\%).

\begin{tabular}{|c|c|c|c|c|c|c|c|c|c|c|}
\hline \multirow{3}{*}{ Compounds } & \multirow{3}{*}{$\mathrm{RT} / \mathrm{min}$} & \multicolumn{9}{|c|}{ Concentration (\%) } \\
\hline & & \multicolumn{9}{|c|}{ Extract (see Table 1) } \\
\hline & & I & II & III & IV & $\mathbf{V}$ & VI & VII & VIII & IX \\
\hline Benzaldehyde & 8.34 & 0.32 & 0.52 & 0.1 & - & - & 0.21 & - & - & - \\
\hline 1,8-cineole & 10.69 & 0.3 & 0.22 & 0.6 & 0.05 & - & 0.19 & - & - & - \\
\hline Borneol & 17.03 & - & - & 0.05 & - & 0.37 & 0.46 & 0.1 & 0.11 & - \\
\hline$\alpha$-Terpineol & 17.27 & - & 0.26 & 0.14 & - & 0.78 & 0.79 & 0.22 & 0.08 & 0.31 \\
\hline Cis-Cinnamaldehyde & 18.77 & - & - & - & - & 2.06 & 0.68 & 0.13 & 0.06 & - \\
\hline Trans-Cinnamaldehyde & 19.41 & 12.51 & 29.29 & 50.33 & 10.19 & 80.72 & 75.79 & 84.04 & 87.66 & 84.42 \\
\hline$\alpha$-Copaene & 22.83 & 2.23 & 2.24 & 3.16 & 0.42 & 0.14 & 2.01 & 1.24 & 1.17 & 1.13 \\
\hline Bergamotene & 24.03 & 0.45 & 0.45 & 0.59 & 0.08 & 0.07 & 0.72 & 0.31 & 0.3 & 0.67 \\
\hline$\beta$-Caryophyllene & 24.30 & 1.94 & 1.19 & 1.26 & 0.18 & 0.13 & 0.83 & 0.75 & 0.81 & 0.97 \\
\hline Coumarin & 24.88 & 0.35 & 1.31 & 1.80 & 0.98 & 11.77 & 8.25 & 10.80 & 7.10 & 5.99 \\
\hline$\alpha$-Humulene & 25.43 & 0.54 & 0.22 & 0.21 & - & - & - & - & - & - \\
\hline$\alpha$-Amorphene & 27.39 & 0.27 & 0.34 & 0.53 & 0.05 & 0.07 & 0.63 & 0.42 & 0.39 & 0.52 \\
\hline Trans -Calamenene & 27.494 & 0.23 & - & 0.22 & - & 0.07 & 0.51 & 0.23 & 0.26 & 0.39 \\
\hline Trans-o-Metoxy cinnamaldehyde & 27.76 & - & - & - & - & 0.36 & 0.42 & - & - & \\
\hline Murrolene & 27.63 & - & 0.07 & 0.28 & - & 0.06 & 0.79 & 0.35 & 0.48 & 0.3 \\
\hline Cadina-1,4-diene & 27.85 & 0.18 & 0.06 & 0.13 & - & - & 0.11 & - & - & - \\
\hline
\end{tabular}

- not detected

The chemical structures of the above-mentioned compounds are shown in Figure 2.

It was found that the main components in all the analyzed extracts are as follows: trans-cinnamaldehyde and coumarin, whose content in the extracts is $(12.51 \%-87.66 \%)$ and $(0.35 \%-11.77 \%)$, respectively. There also is $\alpha$-copaene $(0.13 \%-3.16 \%)$ and $\beta$ - caryophyllene $(0.13 \%-1.94 \%)$ present in large quantities.
The major constituents identified in this study have also been reported in some previous studies related to the chemical analyses of $C$. cassia. For instance, major compounds present in the ethyl acetate extract from the bark of C. cassia were cinnamaldehyde $(38.81 \mathrm{mg} / \mathrm{g})$, coumarin $(6.5 \mathrm{mg} / \mathrm{g})$, and copaene $(5.27 \mathrm{mg} / \mathrm{g})^{42}$.Yang et al. ${ }^{43}(2012)$ found that the major compounds isolated from the bark of C.cassia were cinnamaldehyde (57-69\%), cumarin (4-21\%), and naphthalene (3-14\%). In another study. Jayatilaka et al. ${ }^{44}$ 
(1995) also reported 25 compounds from the bark of cinnamon with trans -cinnamaldehyde (92-98\%), cis- cinnamaldehyde (0.8-2.7\%), $\beta$-caryophyllene $(0.4-3.6 \%)$, coumarin $(0.1-1.6 \%)$ and $\alpha$-ylangene $(0.1-2.7 \%)$ as their major compounds.<smiles>O=C/C=C/c1ccccc1</smiles>

$\mathbf{F}$<smiles>CC1=CC[C@@H](C(C)C)[C@@H]2[C@@H]1[C@@H]1CC=C(C)[C@@H]2C1</smiles>

H<smiles>O=c1ccc2ccccc2o1</smiles>

G

I

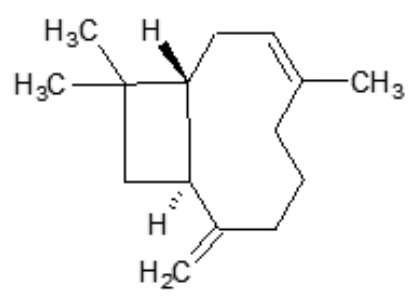

Figure 2. Chemical structures of the four major compounds identified in extracts from the bark of Cinnamomum cassia; (E)-cinnamaldehyde (F), coumarin (G), $\alpha$-copaene $(\mathrm{H}), \beta$ - caryophyllene (I).

It was found that the extracts obtained with tris (2-hydroxyethyl) methylammonium methylsulfate (E) and organic solvents (hexane, ethyl acetate, dichloromethane, ethanol) contained the largest amount of transcinnamaldehyde. Furthermore, it was shown that the contents of coumarin in the extracts obtained with tris (2-hydroxyethyl) methylammonium methylsulfate (E) and ethyl acetate were higher than in other compositions. The best extractants of caryophyllene and copaene proved to be ionic liquids with benzalkonium cation (A and $\mathbf{C})$. Slightly worse results in the extraction of terpenes were obtained using didecyldimethyl lactate (B). Trans -cinnamaldehyde and coumarin belong to alkyl aryl carbonyl compounds and the other compounds belong to terpenes. The results of the experiment indicate that tris (2-hydroxyethyl) methylammonium methylsulfate (E) and organic solvents are the preferred option for extracting alkyl aryl carbonyl compounds and ionic liquids $(\mathbf{A}, \mathbf{B}, \mathbf{C})$ are more suitable for extracting terpene compounds.

\section{Antifungal and yeasticidal activity}

The yeasticidal and antifungal activities of test extracts were examined at the concentration of $5 \mathrm{mg} / \mathrm{ml}$, and the results were presented in Table 3 and Table 4, respectively.

In general, extracts V-IX, revealed yeasticidal activities against Candida albicans, Rhodotorula rubra and Malassezia furfur. However, extracts $\mathbf{V}$ and VI, exhibited higher activities than extracts VII-IX. Extracts I and IV did not reveal any activity against the tested yeast strains. The most potent activity was revealed by extract $\mathbf{V}$ with the values higher than found for ketoconazole and the other reference substances.
Table 3. Diameter of growth inhibition zone (in $\mathrm{mm}$ ) of yeasts strains treated with different extracts from C. cassia and reference substances.

\begin{tabular}{|c|c|c|c|}
\hline \multirow{2}{*}{$\begin{array}{c}\text { Extract (see } \\
\text { Table 1) }\end{array}$} & \multicolumn{3}{|c|}{ Zone of inhibition (mm) } \\
\cline { 2 - 4 } & $\begin{array}{c}\text { Candida } \\
\text { albicans }\end{array}$ & $\begin{array}{c}\text { Rhodotoruin } \\
\text { rubra }\end{array}$ & $\begin{array}{c}\text { Malassezia } \\
\text { furfur }\end{array}$ \\
\hline \multirow{2}{*}{ I } & 0 & 0 & 0 \\
\hline II & $12.73 \pm 2.3$ & $13.2 \pm 2.8$ & $14.5 \pm 0.5$ \\
\hline III & $14.5 \pm 0$ & $15.0 \pm 1.7$ & $14.5 \pm 0.2$ \\
\hline IV & 0 & 0 & 0 \\
\hline V & $50 \pm 0$ & $50 \pm 0$ & $45.5 \pm 0.9$ \\
\hline VI & $37.7 \pm 0.96$ & $39.0 \pm 0$ & $35.0 \pm 0$ \\
\hline VII & $28.6 \pm 0.34$ & $30.5 \pm 1.8$ & $29.0 \pm 0.4$ \\
\hline VIII $^{\prime}$ & $25.0 \pm 1.5$ & $23.5 \pm 0$ & $23.5 \pm 0.3$ \\
\hline IX $^{\text {II }}$ & $22.2 \pm 0.3$ & $19.5 \pm 1.5$ & $23.0 \pm 0$ \\
\hline CA $^{\text {a) }}$ & $20.75 \pm 2.98$ & $23.7 \pm 2.5$ & $20.0 \pm 0$ \\
\hline CU $^{\text {b) }}$ & $26.0 \pm 1.4$ & $10.0 \pm 0$ & $25.0 \pm 1.15$ \\
\hline KET $^{\text {c) }}$ & $37.5 \pm 2.9$ & $36.25 \pm 2.5$ & $18.3 \pm 0.58$ \\
\hline
\end{tabular}

Reference substance; $\mathrm{CA}^{\text {a) }}$ - Cinnamaldehyde, $\mathrm{CU}^{\mathrm{b})}$ - Coumarin $\mathrm{KET}{ }^{\mathrm{c}}$ Ketoconazole

It was found that extracts I and IV had the weakest activity against plant and bee pathogenic fungi, as well as to fungi responsible for degradation of technical materials. The highest activity plant and bee pathogenic fungi, fungus of bees and corrosion fungal species was shown by extracts obtained with tris (2-hydroxyethyl) methyloammonium methylsulfate (E) and hexane. Extracts obtained using ionic liquids with (B) and (C) showed slightly weaker activity against fungal plant pathogens and pathogens causing biodeterioration of technical materials than extracts obtained by tris (2-hydroxyethyl) methylammonium (E) and organic solvents. Extracts III, V, VI-IX showed strong activity against dermatophytes, while extracts I and IV showed weak or moderate effect. The excellent activity against the most tested fungi was also demonstrated by trans- cinnamaldehyde and coumarin. Previous literature has reported that cinnamaldehyde and coumarin were equally effective in inhibiting the growth of various isolates of filamentous moulds, yeasts, dermatophytes and plant pathogenic fungi ${ }^{45-47}$. The results showed that extracts from the bark of C. cassia V-IX demonstrate excellent antifungal activity associated with the presence of trans- cinnamaldehyde, coumarin as the main constituents. Furthermore, it was observed that the biological activity is directly proportional to the contents of the above-mentioned components in the extracts. Extracts I-IV, which are characterized by a relatively low content of coumarin and trans-cinnamaldehyde in their composition, exhibited the weakest biological activity. Although the V-IX extracts contain approximately equal amounts of trans -cinnamaldehyde and coumarin in their composition, extract $\mathbf{V}$ showed the strongest biological activity among them all. It is believed that this may be due to the presence of small amounts of other compounds, e.g. o-metoxy cinnamaldehyde and cis-cinnamaldehyde, or other compounds that may have the effect of increasing the fungicidal and yesticidal activity of the extract. There are indications that these trace compounds play a key role in the antimicrobial properties, most likely due to synergistic effects with other components of the extracts. However, it is extremely difficult to investigate the synergistic effects and interdependencies between all the compounds present in the extracts.

\section{CONCLUSION}

Based on the results, it can be concluded that the extract from the bark of C. cassia obtained with tris (2-hydroxyethyl) methyloammonium methylsulfate as solvent had a stronger antimicrobial activity than the other tested extracts. This study also demonstrated that tris (2-hydroxyethyl) methyloammonium methylsulfate is the best solvent for the extraction of the main antimicrobial constitutes trans-cinnamaldehyde, coumarin from cinnamon. Furthermore, it was found that ionic liquids with benzalconium cation are the best solvents for extraction of terpene compounds (monterpenes and sesquiterpenes). This in vitro study supports the role of the extracts from $C$. cassia as efficient, natural yeasticidal and antifungal agents. 
Table 5. Effect of extracts from C. cassia and reference substances against fungi.

\begin{tabular}{|c|c|c|c|c|c|c|c|c|c|c|c|c|}
\hline \multirow{3}{*}{ Test strain } & \multicolumn{12}{|c|}{ Inhibition of test fungi growth (\%) } \\
\hline & \multicolumn{9}{|c|}{ Extract (see Table 1) } & \multicolumn{3}{|c|}{ Reference substances } \\
\hline & $\mathbf{I}$ & II & III & IV & $\mathbf{V}$ & VI & VII & VIII & IX & $\mathbf{C A N}^{\text {a) }}$ & $\mathbf{C} \mathbf{U}^{\mathrm{b})}$ & $\mathrm{KET}^{\mathrm{c})}$ \\
\hline Fusarium culmorum & $17 \pm 4.2$ & $35 \pm 0.3$ & $42 \pm 5.0$ & $21 \pm 4.5$ & 100 & $71 \pm 9.5$ & $51 \pm 9.5$ & $48 \pm 4.0$ & $45 \pm 1.4$ & 100 & $64 \pm 0.9$ & $80 \pm 3.05$ \\
\hline Phytophthora cactorum & 0 & $50 \pm 1.3$ & $57 \pm 9.3$ & $16 \pm 4.0$ & $68 \pm 5.4$ & $60 \pm 1.3$ & $61 \pm 13$ & $67 \pm 1.5$ & $50 \pm 1.8$ & $78 \pm 2.9$ & $58 \pm 0,7$ & $68 \pm 7.5$ \\
\hline Fusarium graminearum & $15 \pm 2.0$ & $32 \pm 0.9$ & $40 \pm 3.2$ & $30 \pm 5.0$ & 100 & $69 \pm 4.5$ & $58 \pm 2.5$ & $60 \pm 3.2$ & $55 \pm 2.4$ & $27 \pm 2.0$ & $67 \pm 0.7$ & $51 \pm 2.8$ \\
\hline Rhizoctonia solani & $5 \pm 1.2$ & $45 \pm 0.5$ & $55 \pm 2.0$ & 0 & $90 \pm 0$ & $78 \pm 1.3$ & $65 \pm 1.8$ & $68 \pm 2.0$ & $60 \pm 1.4$ & $55 \pm 1.3$ & $45 \pm 0.9$ & $30 \pm 8.0$ \\
\hline Alternaria alternata & $5.4 \pm 0.5$ & $35 \pm 0$ & $49 \pm 9.0$ & $11 \pm 6.0$ & $88 \pm 0$ & $70 \pm 0$ & $63 \pm 0.4$ & $67 \pm 2.0$ & $58 \pm 2.5$ & $59 \pm 4.7$ & $68 \pm 0,5$ & $68 \pm 2.51$ \\
\hline Geumannomyces graminis & $20 \pm 4.0$ & $52 \pm 0.6$ & 100 & $35 \pm 0$ & 100 & 100 & 100 & 100 & 100 & 100 & 100 & 100 \\
\hline Trichophyton mentagrophytes & $51 \pm 0.2$ & $82 \pm 0.9$ & 100 & $50 \pm 0$ & 100 & 100 & 100 & 100 & 100 & 100 & 100 & 100 \\
\hline Microsporum gypseum & $30 \pm 0.5$ & $79 \pm 1.3$ & 100 & $48 \pm 7.5$ & 100 & 100 & 100 & 100 & 100 & 100 & 100 & $73 \pm 2.8$ \\
\hline Microsporum coockei & $32 \pm 0.9$ & $70 \pm 0.7$ & 100 & $50 \pm 6.0$ & 100 & 100 & 100 & 100 & 100 & 100 & 100 & $75 \pm 2.6$ \\
\hline Scopulariopsis brevicualis & $10 \pm 3.6$ & $30 \pm 1.4$ & $32 \pm 1.5$ & $22 \pm 1.5$ & $93 \pm 1.0$ & $72 \pm 2.3$ & $42 \pm 2.8$ & $48 \pm 2.3$ & $45 \pm 1.3$ & $100 \pm 0$ & $30 \pm 2.9$ & $50 \pm 2.3$ \\
\hline Aspergillus niger & $9 \pm 2.5$ & $15 \pm 0.7$ & $18 \pm 2.3$ & $4.5 \pm 1.2$ & $40 \pm 2.3$ & $25 \pm 2,2$ & $20 \pm 2.0$ & $25 \pm 1.3$ & $28 \pm 2.2$ & $50 \pm 0.8$ & $36 \pm 2.9$ & $21 \pm 2.9$ \\
\hline Chaetomium globusom & $29 \pm 1.7$ & $45 \pm 5.7$ & $45 \pm 1.5$ & $35 \pm 0.5$ & 100 & $75 \pm 2.5$ & $68 \pm 1.5$ & $60 \pm 1.5$ & $62 \pm 1.8$ & $52 \pm 2.1$ & $60 \pm 3.9$ & $53 \pm 1.0$ \\
\hline Paecilomyces varioth & 0 & $29 \pm 3.5$ & $30 \pm 3.2$ & $25 \pm 2.8$ & $68 \pm 5.0$ & $46 \pm 3.4$ & $36 \pm 3.4$ & $40 \pm 3.5$ & $42 \pm 1.8$ & $50 \pm 2.0$ & $60 \pm 3.9$ & $66 \pm 4.0$ \\
\hline Ascosphaera apis & 0 & $20 \pm 4.9$ & $31 \pm 0.3$ & 0 & 100 & $77 \pm 14$ & $67 \pm 14$ & $60 \pm 1.0$ & $55 \pm 0.5$ & 100 & 100 & $45 \pm 2.9$ \\
\hline
\end{tabular}

Reference substance; $\mathrm{CA}^{\text {a) }}$ - Cinnamaldehyde , $\mathrm{CU}^{\mathrm{b}}$ - Coumarin $\mathrm{KET}^{\mathrm{c}}{ }^{\mathrm{c}}$ - Ketoconazole

\section{ACKNOWLEDGMENTS}

This research was supported by the Polish Committee of Scientific Research (grant No N N209 095435).

\section{REFERENCE}

1. J. Choi, K. T. Lee, H. Ka, W. T. Jung, H. J. Jung, H. J. Park,. Arch. Pharm. Res. 24, 418, (2001)

2. L. Wang, Z. M. Wang, T. C. Li, X. Zhou, L. Ding, H. Q. Zhang, Chem. Res. Chin. Univ. 24, 275, (2008)

3. C. Liu , S. M. Zhong, R. Y. Chen, Y. Wu, X. J. Zhu, J. Asian Nat. Prod. Res. 11, 845, (2009)

4. N. Masood, A. Chaudhry, P. Tariq, Pak. J. Bot. 38, 169, (2006)

5. R. Giordani, P. Regli, J. Kaloustian , H. Portugal, Phytother.Res. 20, 58, (2006)

6. L. S. Ooi,Y. Li, S. L. Kam, H. Wang, E. Y. Wong, V. E. Ooi, Am. J. Chin Med. 34, 511, (2006)

7. S. H. Lee, K. S. Chang, M. S. Su, Y. S. Huang, H. D. Jang, Food Control. $18,1547,(2007)$

8. D. Thanaboripat, Y. Suvathi, P. Srilohasin, S. Sripakdee, O. Patthanawanitchai and S. Charoensettasilp KMITL Sci. Tech. J.7, 1, (2007)

9. D. Kocevski, Du M, J. Kan, C. Jing, I. Lačanin, H. Pavlović, J. Food Sci. 78, 731, (2013)

10. S. J. Koppikar, A. S. Choudhari, S. A. Suryavanshi, S. Kumari, S. Chattopadhyay, R. Kaul-Ghanekar, BMC Cancer. 18, 210, (2010)

11. S. I. Kim, J. Y. Roh, D. H. Kim, H. S. Lee, Y. J. Ahn, J. Stored Prod. Res. 39, 293, (2003)

12. K. S. Chang, J. H. Tak, S. I. Kim, W. J. Lee, Y. J. Ahn., Pest Manag. Sci.
$62,1032,(2006)$

13. H. D. Ouden, D. P. W. Alkema, J. W. Klijnstra, J. Theunissen, J. J. Vlieger, J Appl. Entomol. 121, 275, (1997)

14. X. Wang, Q. Li, L. Shen, J. Yang, H. Cheng, S. Jiang, Ch. Jiang, H. Wang, J. Insect Sci.14, 1, (2014)

15. Q. Luo, S. M. Wang, Q. Lu, J. Luo, Y. X. Cheng, Molecules, 18, 10930, 2013

16. H. Tabassum, M. N. Ali, N. Al-Jameil, F. A. Khan, Int. J.Curr. Microbiol. App.Sci. 2, 353, (2013).

17. N. N. Kasim, S. N. A. S. Ismail, N. D. Masdar, F. Ab Hamid, W. I. Nawawi, I.J.S.R. 4, 1, (2014)

18. W. Liu, L. Cheng, Y. Zhang., H. Wang, M. Yu, J. Mol. Liq. 140, 68, (2008)

19. J. Fuller, R. T. Carlin, R. A. Osteryoung,. J. Electrochem. Soc.144, 3881, (1997)

20. M. Regel-Rosocka, Sep. Purif. Technol. 66, 19, (2009).

21. U. Domańska, A. Rękawek, J. Solution Chem.38, 739, (2009)

22. A. Cieszyńska. M. Wiśniewski, Sep. Purif. Technol. 73, 202, (2010)

23. H. Han D. W. Armstrong, Acc. Chem. Res. 40, 1079, (2007)

24. A. Seeberger, A. Jess, Green Chem. 12, 602, (2010)

25. Ch. Huang, B. Chen, J. Zhang, Z. Liu, Y. Li, , Energ Fuel. 18, 1862, (2004)

26. F. Y. Du, X. H. Xiao, G. K. Li, J. Chromatogr. A 1140, 56, (2007)

27. P. Wang, C. Ma, S. Chen, S. Zhu, Z. Lou, H. Wang, Trop. J. Pharm. Res. $13,1339,(2014)$

28. H. Zeng, Y. Wang, J. Kong, Ch. Nie, Y. Yuan, Talanta, 83, 582, (2010)

29. X. Cao, X. Ye, Y. Lu, Y. Yu, W. Mo, Anal. Chim. Acta, 640, 47, (2009)

30. W. Ma, Y. Lu, R. Hua , J. Chen, Z. Zhang, Y. Pan, Talanta, 80, 1292, (2010)

31. A. Cieniecka - Rosłonkiewicz, A.Sas, E. Przybysz, B. Morytz, A. Syguda, J. Pernak, Chem. Biodivers. 4, 2218, (2007)

32. J. Cybulski, A. Wiśniewska, A. Kulig-Adamiak, L. Lewicka, A. 
Cieniecka-Rosłonkiewicz, K. Kita, A. Fojutowski, J. Nawrot, K. Materna , J. Pernak, Eur. J. Chem. 14, 9305, (2008)

33. J. Pernak, M. Smiglak,S. T. Griffin,W.L. Hough, T. B. Wilson, A. Pernak, J. Zabielska-Matejuk, A. Fojutowski, K. Kita, R. G. Rogers, Green Chem. $8,798,(2006)$

34. Y. Massada. Analysis of Essential Oils by Gas Chromatographyn and Mass Sepectrometry. Wiley, New York. USA. NIST/EPA/NIH.Mass Spectral Library, USA 2002

35. R.P. Adams, Identification of eessential oils components by gas chromatography/quadruple mass spectroscopy, 4th edition. Allured Publishing Corporation, Carol Stream, Illinois, USA, 2007

36. H. Van Den Dool, D. J. Kratz, J. Chromatogr. 11, 463, (1963)

37. W. Jennings, T. Shibamoto, Qualitative Analysis of Flavour and Fragrance Volatiles by Glass Capillary Gas Chromatography, Academic Press, New York, 1980

38. W. Davies, J. Chromatogr. 503, 1, (1990)
39. A.W. Bauer, W. M. Kirby, J. C. Sherris, M. Turck, Am. J. Clin.Pathol. 36, 493, (1966)

40. A. Michalczyk, A. Cieniecka-Rosłonkiewicz, M. Cholewińska, Herba Polonica, 4, 22, (2014)

41. W. M. Gołębiewski, M. Cyrta, A. Michalczyk, J. Mycol Med. 14, 1156, (2014)

42. G. P. Lv, W. H. Huang F. Q. Yang, J. Li , S. P. Li, , J. Sep. Sci. 33, 2341, (2010)

43. Ch. H. Yang, R-X Li, L. Y. Chuang, Molecules. 17, 7294, (2012)

44. A. Jayatilaka, S. K. Poole, C. F. Poole, T. M. P. Chichila, Anal. Chim. Acta. 302,147, (1995)

45. L.S. Ooi,Y. Li, S. L. Kam, H. Wang, E.Y. Wong, V. E. Ooi, Am. J. Chin. Med. 34, 511, (2006)

46. H. Ferhout, J. Bohatier, J. Guillot, J. C. Chalchat, J. Essent. Oil Res. 11, $119,(1999)$

47. C. Montagner, S. M. de Souza, C. Graposo, F. D. Monache, E. F. A. Smania, A. Jr. Smania , Z. Naturforsch C. 63, 21, (2008) 